Short Communication

\title{
Mycotoxin Contaminants of Walnuts - Preliminary Studies
}

\author{
Małgorzata Tokarska-Rodak ${ }^{1 *}$, Marta Zarębska², Dominik Karol Nitychoruk ${ }^{3}$ \\ ${ }^{1}$ Faculty of Health Sciences, Pope John Paul II State School of Higher Education in Biała Podlaska, Poland \\ ${ }^{2}$ Innovation Research Centre, Pope John Paul II State School of Higher Education in Biała Podlaska, Poland \\ ${ }^{3}$ Faculty of Biology, Adam Mickiewicz University in Poznań, Poland
}

Received: 28 January 2021

Accepted: 15 June 2021

\begin{abstract}
Mycotoxins are important indicators of product quality. They show various levels of toxicity, and contaminated food can cause acute, sub-acute, or chronic food poisoning and exert a negative effect on human health. The aim of the study was to determine the concentration of selected mycotoxins: total aflatoxins, aflatoxin B1, ochratoxin A, fumonisin, T-2/HT-2 toxins, and zearalenone in walnuts collected in private household gardens in Lublin Province. Walnut (in shells) were collected in June/July 2020. The material, i.e. 38 walnut samples from autumn harvest in 2019, was donated for the analyses voluntarily. Quantitative tests ELISA were used to detect the presence of mycotoxins in the edible part of the nuts. Over $86 \%$ of the walnut samples were found to exceed the maximum residue levels for the total aflatoxin concentration $(4 \mu \mathrm{g} / \mathrm{kg}$ ) for tree nuts intended for human consumption or used as an ingredient in food products. The concentration of aflatoxin B1 exceeded the allowable level of $2 \mu \mathrm{g} / \mathrm{kg}$ in over $65 \%$ of the samples. In addition to aflatoxins, two other mycotoxins (ochratoxin A and T-2/HT-2) were detected in over $28 \%$ of the samples, three compounds (ochratoxin A, fumonisin, and T-2/HT-2) - in $15.8 \%$ of the samples, and ochratoxin A, T-2/HT-2, and zearalenone were contained in $10.5 \%$ of the samples. Aflatoxin is the most common fungal contaminant of walnuts however other mycotoxins, may be identified in this product as well. Potentially they all exert an unfavorable impact on consumer health..
\end{abstract}

Keywords: mycotoxin, walnuts, aflatoxin B1 (AFB1), ochratoxin A (OTA), zearalenone (ZON)

\section{Introduction}

Aspergillus spp., Penicillium spp., and Fusarium spp. are the dominant genera of filamentous fungi affecting the quality of crops and crop food products considerably [1]. These filamentous fungi not only

*e-mail: rodak.malgorzata@gmail.com reduce the organoleptic and nutritional values of food products but are also a source of mycotoxins, i.e. lowmolecular weight $(<1.5 \mathrm{kDa})$ secondary metabolites [2]. Mycotoxins are important indicators of product quality. They are characterized by various levels of toxicity. Contaminated food or fodder can cause acute, subacute, or chronic food poisoning and exert a negative effect on human and animal health. Mycotoxins have also been shown to have neurotoxic, hepatotoxic, 
nephrotoxic, teratogenic, carcinogenic, and estrogenic activity [2-8].

The most common mycotoxins contaminating food and posing a health risk are aflatoxins, i.e. a group of 20 heterocyclic difurocoumarin derivatives produced by Aspergillus flavus, A. parasiticus, A. nomins, $A$. bombycis, A. pseudotamarii, A. ochraceoroseus, $A$. rambellii, A. anamorphs, and Emericella venezuelensis. Aflatoxins (AF): AFB1, AFB2, AFG1, and AFG2 have been identified in food or fodder most frequently, and AFB1 has been shown to have the highest toxicity. Aflatoxins AFM1 and AFM2 are hydroxyl metabolites of AFB1 and AFB2 detected in milk and dairy products [1, 8-10]. These compounds have carcinogenic and genotoxic activity, cause acute hepatitis, and affect the functions of the immune system [2, 4-6, 11].

Other mycotoxins compromising food safety are ochratoxin A (OTA), zearalenone (ZON), fumonisin, and trichothecenes. Ochratoxin A produced by Aspergillus ochraceus, A. melleus, A. sulphureus, A. allianus, A. sclerotium, Penicillium verrucosum, and $P$. viiridicatum exerts teratogenic, carcinogenic, hepatotoxic, and neurotoxic effects. Zearalenone produced by Fusarium graminearum, $F$. roseum, $F$. culmorum, F. crookwellense, F. cerealis, F. equiseti, and $F$. semitectum has estrogenic activity. In turn, fumonisins produced by Fusarium moniliforme and $F$. proliferatum have hepatotoxic and carcinogenic properties. Deoxynivalenol (DON) is produced by Fusarium poae, F. sporotrichoides, F. crookwellense, F. culmorum, and F. graminearum, whereas Microdochium nivale syn. F. nivale fungi produce nivalenol. These compounds exert immunosuppressive, mutagenic, and teratogenic effects and may cause gastrointestinal hemorrhage. Other mycotoxins that affect food safety include patulin (PT), which causes pulmonary and cerebral hemorrhage, and sterigmatocystin (ST), which causes diarrhea and changes in kidneys and liver and has a carcinogenic effect $[2,4-6,10,12]$. Moreover, mycotoxins may exert dermatotoxic (trichothecenes) and cardiotoxic (moniliformin) effects [12].

Removal of visible hyphae from products does not eliminate mycotoxins. However, the presence of a fungal pathogen does not mean that the product must contain mycotoxins. Obviously, a contaminated raw material yields a contaminated product; hence, mycotoxins can enter the human or animal organism via a primary route (consumption of grain, seeds, nuts, fruit, spices, and fodder). Mycotoxins can also enter the human organism via a secondary route through the consumption of meat, eggs, and milk originating from animals that consume fodder contaminated with these toxins [2]. Many mycotoxins are not sensitive to elevated temperatures and are therefore not neutralized by heat treatment, which further impedes elimination thereof from products. However, they are degraded in an alkaline environment and by UV radiation [2,9].

Various cereal grains and cereal products (e.g. flour, groats, bran, and bread), legume seeds, nuts, oil seeds and oils, dried fruit, fruit juices, wine, beer, coffee beans, cocoa, dried tea leaves, and spices have been reported to contain mycotoxins [2, 4]. The maximum allowable levels of certain contaminants in foodstuffs are regulated by Regulation No. 1881/2006 [13]. Agricultural products can be contaminated with mycotoxins during both the plant vegetation period and storage in inappropriate conditions. Storage of food products, e.g. dried fruit and nuts, at variable (uncontrolled) humidity and temperature may result in the growth of molds and contamination by mycotoxins $[2,10]$.

Walnuts (Juglans regia L., genus Juglans, family Juglandaceae) are very often stored in household conditions [14-15]. The fruit consists of an outer green husk, a central shell, a thin seed skin, and a kernel. The walnut is regarded as a strategic species in human nutrition, and the Food and Agriculture Organization (FAO) has assigned the species into the group of priority plants. Walnuts are a source of tocopherols, essential fatty acids (linoleic, linolenic, palmitic, oleic, and stearic acids), flavonoids, polyphenols, tannins, folic acid, dietary fiber, protein, melatonin, sterols, and juglone representing the group of naphthoquinones [15]. Walnuts can be consumed in a fresh and dried form or as oil pressed from the kernels. Therefore, the quality of nuts intended for consumption is essential, as the raw material should not contain compounds that exert a negative impact on human health, e.g. mycotoxins [12]. Walnuts are susceptible to the growth of molds, which is associated with such environmental factors as temperature and humidity as well as their nutrient content, $\mathrm{pH}$, improper harvesting practices, and longterm storage in inappropriate conditions [16-17]. Aspergillus spp., Rhizopus spp., and Penicillium spp. are isolated from walnuts most frequently [16].

The ability of mold fungi to produce mycotoxins is not a permanent species-specific trait [12]. In certain environmental conditions, this ability may be lost by a given strain, or a so-far non-toxigenic strain may start to produce toxins. It is assumed that the mycotoxin production ability may be triggered by environmental stress conditions, e.g. changes in temperature, humidity, or oxygen access, or by the action of substances that are aggressive to fungi [7].

The aim of the study was to determine the concentration of selected mycotoxins, i.e. total aflatoxins, aflatoxin B1, ochratoxin A (OTA), fumonisin, T-2/HT-2 toxins, and zearalenone (ZON) in walnuts collected in private household gardens in Lublin Province.

\section{Material and Methods}

\section{Material Collection}

Walnuts (in shells) were collected in household gardens in Lublin province in June/July 2020. The 
material, i.e. 38 walnut samples from autumn harvest in 2019, was donated for the analyses voluntarily. The sampling procedure was carried out in compliance with the principle that the samples should be representative for a given batch of the product [18]. Each sample of walnuts was placed in a clean chemically inert container ensuring adequate protection from contamination and damage during transport. The laboratory analyses were performed in batches to minimize the time of the sample storage in the laboratory. The samples were protected from sunlight.

\section{ELISA Analysis of Mycotoxins}

The quantitative ELISA tests, i.e. Bio-Shield Total ES, Bio-Shield-B1, Bio-Shield-Ochratoxin; Bio-Shield ZON, Bio-Shield-Fumonisin, and Bio-Shield-T2-HT2 from ProGnosis Biotech S.A. (Greece), were designed for detection of mycotoxins in grains, cereals, spices, and other commodities, including animal feeds. The levels of total aflatoxins, AFB1, OTA, fumonisin, T-2/HT-2, and ZON were determined in the edible part of the walnuts. The quantitative tests were based on the enzyme linked immunosorbent assay principles and were performed according to the manufacturer's recommendations.

Preparation of samples for testing: toxins were extracted from a ground kernel sample (20 g) with $70 \%$ methanol $(100 \mathrm{ml})$ and mixed in a blender for a minimum of 2 minutes. The mix was filtered using filter paper; $50 \mu \mathrm{l}$ of each filtrate was used directly in the immunoassay. In the Bio-Shield Total ES (ProGnosis Biotech S.A) tests, the wells of the microtiter strips were coated with total aflatoxin specific antibodies. In turn, the wells were coated with AFB1 specific antibodies in the Bio-Shield B1 (ProGnosis Biotech S.A) tests,. In the Bio-Shield Ochratoxin, Bio-Shield ZON, Bio-ShieldFumonisin, and Bio-Shield-T2-HT2 (ProGnosis Biotech S.A) tests, the wells of the microtiter strips were coated with specific antibodies for ochratoxin A (OTA), zearalenone ( $\mathrm{ZON})$, fumonisin, and $\mathrm{T}-2$, respectively.

The absorbance value of each test was read on a spectrophotometer at $450 \mathrm{~nm}$ as the primary wavelength.
The intensity of the produced colored complex was indirectly proportional to the concentration of the mycotoxin (total aflatoxin/aflatoxin B1/OTA/ZON/ fumonisin/and T2-HT2) present in the samples and standards. Equipment: Microtiter plate reader fitted with a $450 \mathrm{~nm}$ filter (ThermoScientific Multiskan FC) and SkanIt Software 3.1 Research Edition for Multiskan FC.

The levels of total aflatoxins and AFB1 in the walnuts were assessed in terms of exceeding the maximum residue limits (MRLs) specified by the applicable Regulation No. 165/2010 [19].

\section{Results and Discussion}

Detailed results of the amounts of mycotoxins (total aflatoxins, AFB1, and the other mycotoxins) in the edible part of the walnuts are summarized in Table 1, Table 2, and Table 3.

\section{Aflatoxins In Walnut Kernels}

Over $86 \%$ of the walnut samples were found to exceed the MRL for the total aflatoxin concentration ( $4 \mu \mathrm{g} / \mathrm{kg}$ ) for tree nuts intended for human consumption or used as an ingredient in food products. Similarly, the concentration of AFB1 exceeded the allowable level of $2 \mu \mathrm{g} / \mathrm{kg}$ in over $65 \%$ of the samples (Table 1 ).

Aflatoxins are the main mycotoxins produced in improperly stored nuts. Their maximum levels are specified by Commission Regulation (EU) No. 165/2010 [19]. The maximum allowable level is limited to $5.0 \mu \mathrm{g} / \mathrm{kg}$ for aflatoxin B1 and $10.0 \mu \mathrm{g} / \mathrm{kg}$ for total aflatoxins (B1, B2, G1, and G2) in tree nuts (other than almonds, pistachios, apricot kernels, hazelnuts, and Brazil nuts) intended to be sorted, physically processed before human consumption, or used as an ingredient in foodstuffs. These values in the case of hazelnuts and Brazil nuts are $8.0 \mu \mathrm{g} / \mathrm{kg}$ (aflatoxin B1) and $15.0 \mu \mathrm{g} / \mathrm{kg}$ (sum of aflatoxins B1, B2, G1, and G2) [19].

Tree nuts (other than almonds, pistachios, apricot kernels, hazelnuts, and Brazil nuts) and processed nut

Table 1. Total concentration of aflatoxins (total AF) and aflatoxin B1 (AFB1) in the edible part of walnuts.

\begin{tabular}{|c|c|c|c|c|c|c|c|}
\hline \multirow{3}{*}{ Mycotoxins } & \multicolumn{3}{|c|}{$\mathrm{N}=38$} & \multirow{2}{*}{\multicolumn{2}{|c|}{$>\operatorname{MRL}[\%]$}} & \multirow{2}{*}{\multicolumn{2}{|c|}{$\operatorname{MRL}[\mu \mathrm{g} / \mathrm{kg}]^{1}$}} \\
\hline & \multicolumn{3}{|c|}{ Concentration $[\mu \mathrm{g} / \mathrm{kg}]$} & & & & \\
\hline & Average & Min. & Max. & MRL (I) & MRL (II) & MRL (I) & MRL (II) \\
\hline AF total & 4,8 & 2,7 & 8,6 & 0 & 86,8 & 10 & 4 \\
\hline AFB1 & 2,5 & 1,6 & 4,6 & 0 & 65,8 & 5 & 2 \\
\hline
\end{tabular}

${ }^{1}[19]$

MRL- maximum residue levels

MRL (I) - Tree nuts, other than the tree nuts listed in 2.1.2 and 2.1.3, to be subjected to sorting, or other physical treatment, before human consumption or use as an ingredient in foodstuffs

MRL (II) -Tree nuts, other than the tree nuts listed in 2.1.6 and 2.1.7, and processed products thereof, intended for direct human consumption or use as an ingredient in foodstuffs 
Table 2. Presence of total aflatoxins (total AF), aflatoxin B1 (AFB1) and other mycotoxins in walnut kernels.

\begin{tabular}{|c|c|c|c|c|c|c|c|c|c|c|c|c|}
\hline \multicolumn{10}{|c|}{ Mycotoxins in walnuts } \\
\hline Total AF & $\mathrm{X}$ & $\mathrm{X}$ & $\mathrm{X}$ & $\mathrm{X}$ & $\mathrm{X}$ & $\mathrm{X}$ & $\mathrm{X}$ & $\mathrm{X}$ & $\mathrm{X}$ & $\mathrm{X}$ & $\mathrm{X}$ & $\mathrm{X}$ \\
\hline AFB1 & $\mathrm{X}$ & $\mathrm{X}$ & $\mathrm{X}$ & $\mathrm{X}$ & $\mathrm{X}$ & $\mathrm{X}$ & $\mathrm{X}$ & $\mathrm{X}$ & $\mathrm{X}$ & $\mathrm{X}$ & $\mathrm{X}$ & $\mathrm{X}$ \\
\hline Ochratoxin A & & $\mathrm{X}$ & & $\mathrm{X}$ & & & & $\mathrm{X}$ & $\mathrm{X}$ & & $\mathrm{X}$ & $\mathrm{X}$ \\
\hline Fumonisin & & & & & $\mathrm{X}$ & & $\mathrm{X}$ & $\mathrm{X}$ & & $\mathrm{X}$ & $\mathrm{X}$ & $\mathrm{X}$ \\
\hline T-2/HT-2 & & & $\mathrm{X}$ & $\mathrm{X}$ & $\mathrm{X}$ & $\mathrm{X}$ & & & $\mathrm{X}$ & $\mathrm{X}$ & $\mathrm{X}$ & $\mathrm{X}$ \\
\hline Zearalenone & & & & & & $\mathrm{X}$ & $\mathrm{X}$ & & $\mathrm{X}$ & $\mathrm{X}$ & & $\mathrm{X}$ \\
\hline $\mathrm{N}(\%)$ & $2(5,3)$ & $1(2,6)$ & $4(10,5)$ & $11(28,9)$ & $3(7,9)$ & $1(2,6)$ & $2(5,3)$ & $2(5,3)$ & $4(10,5)$ & $1(2,6)$ & $6(15,8)$ & $1(2,6)$ \\
\hline
\end{tabular}

Table 3. Concentration of mycotoxins other than aflatoxin in walnut kernels.

\begin{tabular}{|c|c|c|c|c|}
\hline \multirow{2}{*}{ Mycotoxins } & \multirow{2}{*}{$\mathrm{N}(\%)$} & \multicolumn{3}{|c|}{ Concentration $[\mu \mathrm{g} / \mathrm{kg}]$} \\
\cline { 2 - 5 } & & Average & Min. & Max. \\
\hline \multirow{2}{*}{ Ochratoxin A } & $25(65,8)$ & 3,6 & 1,5 & 5,8 \\
\cline { 2 - 5 } & $13(34,2)$ & $<1,5^{*}$ & - & 249,6 \\
\hline \multirow{2}{*}{ Fumonisin } & $15(39,5)$ & 165,0 & 103,0 & - \\
\cline { 2 - 5 } & $23(60,5)$ & $<100^{*}$ & - & 47,6 \\
\hline \multirow{2}{*}{ T-2/HT-2 } & $31(81,6)$ & 16,6 & - & - \\
\cline { 2 - 5 } & $7(18,4)$ & $<10^{*}$ & 16,0 & 33,7 \\
\hline \multirow{2}{*}{ Zearalenone } & $8(21,1)$ & 22,4 & - & - \\
\hline
\end{tabular}

*Concentration below the quantification threshold of the test

products intended for human consumption or to be used as an ingredient in foodstuffs may contain maximum $2.0 \mu \mathrm{g} / \mathrm{kg}$ of aflatoxin B1 and maximum alflatoxin sum (B1, B2, G1, and G2) of $4.0 \mu \mathrm{g} / \mathrm{kg}$ [19].

The present study demonstrated that these limit values were exceeded in a large part of the analyzed walnuts. The allowable concentrations of the sum of aflatoxins $(4.0 \mu \mathrm{g} / \mathrm{kg})$ and aflatoxin B1 $(2.0 \mu \mathrm{g} / \mathrm{kg})$ were exceeded in over $86 \%$ and over $65 \%$ of the samples, respectively.

Analyses of walnut samples carried out by AdayaGonzález et al. revealed the presence of AFB1 in 22\% of the samples and AFt (total aflatoxins) in 100\% of the analyzed material. The mean concentration of AFB1 and AFt in the walnuts was $0.05 \mathrm{ng} / \mathrm{g}$ and $2.10 \mathrm{ng} / \mathrm{g}$, respectively [20]. In other studies, the presence of aflatoxins was detected with the use of the ELISA assay in $76 \%$ of walnut samples and the following levels were determined: aflatoxin B1 15.4-35.1 $\mu \mathrm{g} / \mathrm{kg}$, aflatoxin B2 4-8.1 $\mu \mathrm{g} / \mathrm{kg}$, aflatoxin G1 $1.4-8.2 \mu \mathrm{g} / \mathrm{kg}$, and aflatoxin G2 up to $5.1 \mu \mathrm{g} / \mathrm{kg}$ [3]. In a study conducted by Gürses, the detectable levels of aflatoxin were $33.4 \mathrm{ppb}$ in hazelnuts, $22.1 \mathrm{ppb}$ in walnuts, and $43.0 \mathrm{ppb}$ in peanuts [21].

A review of research on mycotoxins presented by Kowalska et al. showed that aflatoxins (AF and
AFB1 sum) were detected by many researchers from various countries in many types of products, including nuts. In hazelnuts, the concentrations of $\mathrm{AF}$ and AFB were in the range of $0.625-10 \mathrm{ppb}$ and 10.02-1.47 ppb, respectively. As demonstrated by various experimental data, the concentration of $\mathrm{AF}$ in peanuts was within the range of 0.2-39 ppb and up to $76.76 \mathrm{ppb}$, and the concentration of AFB1 ranged from 0.01 to $0.04 \mathrm{ppb}$. The concentration of total AF in processed products (walnut cream) was estimated at 0.625-10 ppb [9].

\section{Other Mycotoxins in Walnut Kernels}

In addition to total AF and AFB1, other mycotoxins were present in various configurations in $94.7 \%$ of the tested walnuts. Besides aflatoxins, two other mycotoxins, i.e. OTA and T-2/HT-2, were detected in over $28 \%$ of the samples, three compounds, i.e. OTA, fumonisin, and T-2/HT-2 were present in $15.8 \%$ of the samples, and OTA, T-2/HT-2, and ZON were contained in $10.5 \%$ of the samples (Tab. 2). The current regulations do not specify the concentrations of toxins other than aflatoxins in walnuts. Nevertheless, these toxins were present in a measurable concentration in some of the tested samples, as shown in Table 3. 
The maximum allowable level of ochratoxin $\mathrm{A}$ is $5 \mu \mathrm{g} / \mathrm{kg}$ in unprocessed cereals and $3 \mu \mathrm{g} / \mathrm{kg}$ in products derived from unprocessed and processed cereals and cereals intended for direct human consumption [13]. The maximum permissible level of ochratoxin $\mathrm{A}$ is $15 \mu \mathrm{g} / \mathrm{kg}$ in such spices as pepper (Piper spp. fruits, including white and black pepper), nutmeg (Myristica fragrans), ginger (Zingiber officinale), and turmeric (Curcuma longa) and $20 \mu \mathrm{g} / \mathrm{kg}$ in Capsicum spp. (whole or ground dried fruit, including chili peppers, ground chili, cayenne, and paprika) [22].

In the walnut samples analyzed in the present study, the maximum concentrations of ochratoxin $\mathrm{A}$ and zeralenone were $5.8 \mu \mathrm{g} / \mathrm{kg}$ and $33.7 \mu \mathrm{g} / \mathrm{kg}$, respectively. In the group of ochratoxins $\mathrm{A}, \mathrm{B}$, and $\mathrm{C}$, ochratoxin A (OTA) exerts the strongest toxic effect, which is associated with inhibition of enzymes involved in carbohydrate metabolism [5, 12]. Analyses of walnuts $(\mathrm{N}=22)$ carried out by Narváez et al. showed a varied percentage of seven mycotoxins present in all analyzed samples. Alternariol ranging from 0.29 to $1.65 \mu \mathrm{g} / \mathrm{kg}$ was the most common compound (53\%), zearalenone was present at an average level of $0.44 \mu \mathrm{g} / \mathrm{kg}$ in $18 \%$ of the samples, $\alpha$-zearalanol was detected in a concentration range from 2.13 to $2.24 \mu \mathrm{g} / \mathrm{kg}$ in $12 \%$ of the samples, and $\beta$-zearalanol was found at a concentration from 1.67 to $5.24 \mu \mathrm{g} / \mathrm{kg}$ in $18 \%$ of the samples. Additionally, $\beta$-zearalenol, AME (Alternariol monomethyl-ether), and ENNB1 (Enniatin B1) were detected. It has been shown that mycotoxins may occur in various combinations in $45 \%$ of analyzed nut samples [17]. Zaeralenone and its metabolites exhibit structural similarity to estrogen, estrone, and estriol and can interact with human estrogen receptors. This is associated with their potential harmful effects and a possible relationship with the development of neoplasms in the uterus and ovaries [5].

There is growing consumer interest in the quality and composition of food and the presence of harmful compounds in food products. Legal regulations accepted in the European Union countries impose food control obligations on food producers to ensure consumer food safety. One of the groups of food contaminants are mycotoxins, which are not decomposed during storage, as they are chemically stable compounds [2]. As shown by Ciecierska, a majority of reports submitted to the Rapid Alert System for Food and Feed (RASFF) in 2009-2013 indicated the presence of mycotoxins. There were 670 reports in 2009 and 405 in 2013. Exceeded levels of aflatoxins and, less frequently, ochratoxin A were reported most often. Nuts, mainly peanuts and pistachios, were the main products that posed the highest risk of mycotoxin contaminations [23].

As indicated by many reports, the presence of mycotoxins in food products from the category "nuts, nut products, and seeds" in Poland was communicated to the RASFF system 134 times in 2010-2020. Aflatoxins (131 reports) were reported most frequently, whereas the presence of ochratoxin A was documented less often (3 reports) [24].

International Nut and Dried Fruit Council informed that overall walnut production in 2019/2020 reached 965,402 tons (kernel). China was the top producer, accounting for $46 \%$ of the world share followed by the USA $-27 \%$, Chile $-7 \%$, Iran 5\%, Ukraine 5\%, France $-2 \%$, and others $-8 \%$. Control of exported nuts is therefore important [25].

Since many foodstuffs are produced in a traditional way on private farms or in household gardens, the public awareness of the quality of this type of food is important. The quality of nuts, which are often cultivated in household gardens or purchased in openair markets and stored in the house, seems to be an essential issue. It seems that, in the case of humans, the long-term exposure to ingestion of small amounts of the toxins with food, which may have an adverse impact on health, is a serious problem rather than acute mycotoxin poisoning [5]. To prevent mold growth in products effectively and thus reduce the likelihood of mycotoxin contamination, such food products as nuts should be tightly packaged and stored in a dry and cool place [9]. It is vital to prevent food contamination with mycotoxin-producing fungi during harvesting, processing, and storage of products. It seems that an appropriate procedure is the best food control method. Inspection of food packaging, removal of damaged and moldy fruit/nuts, and proper drying before packaging can contribute to the reduction of mold growth and production of mycotoxins [21].

\section{Conclusions}

Aflatoxin is the most common fungal contaminant in walnuts. Other mycotoxins, e.g. ochratoxin A, fumonisin, T-2/HT-2, and zeralenone, may be present in this product as well. Mycotoxins other than aflatoxins have no specified maximum residue levels (MRLs) in the edible part of walnut seeds; therefore, it is not possible to estimate whether their level was exceeded in the samples analyzed in the present study. Potentially, they all exert an unfavorable impact on consumer health.

\section{Conflict of Interest}

The authors declare no conflict of interest.

\section{References}

1. GRUBER-DORNINGER C., NOVAK B., NAGL V., BERTHILLER F. Emerging Mycotoxins: Beyond Traditionally Determined Food Contaminants. J. Agric. Food Chem., 65, 7052, 2017.

2. KOWALSKA G., KOWALSKI R. Control of the presence of mycotoxins in agricultural products and 
food. Part I. A review. Agronomy Science, 75 (3), 19, 2020 [In Polish].

3. SIAHI SHADBAD M.R., ANSARIN M., TAHAVORI A., GHADERI F., NEMATI M. Determination of aflatoxins in nuts of Tabriz confectionaries by ELISA and HPLC methods. Adv. Pharm. Bull., 2 (1), 123, 2012.

4. MRUCZYK K., JESZKA J. Assessment of mycotoxin content in selected food products from the lubuskie province. Bromat. Chem. Toksykol., 1, 89, 2013 [In Polish].

5. POLAK-ŚLIWIŃSKA M., KUBIAK M.S., BOREJSZO Z. Methods for the determination of selected mycotoxins in food and feed®. Postepy Techniki Przetwórstwa Spożywczego, 2, 120-124, 2014 [In Polish].

6. POLAK-ŚLIWIŃSKA M., KUNCEWICZ A. The effect of organic, regional and conventional production on mycotoxins pollution in selected group of food products. Acta Sci. Pol. Technica Agraria, 12 (1-2), 41, 2013 [In Polish].

7. WRÓBEL B. Health risks of animals and humanscaused by toxins of filamentous fungi in feed and food. Woda Środowisko Obszary Wiejskie, 14 (3), 159, 2014 [In Polish].

8. DIELLA G., CAGGIANO G., FERRIERI F., VENTRELLA A., PALMA M., NAPOLI C., RUTIGLIANO S., LOPUZZO M., LOVERO G., MONTANA M.T. Aflatoxin contamination in nuts marketed in Italy: preliminary results. Annali Di Igiene, 30 (5), 401, 2018

9. KOWALSKA A., WALKIEWICZ K., KOZIEŁ P., MUC-WIERZGOŃ M. Aflatoxins: characteristics and impact on human health. Postepy Hig. Med. Dos., 71, 315, 2017.

10. SANTOS PEREIRA C., CUNHA S.C., FERNANDES J. O. Prevalent Mycotoxins in Animal Feed: Occurrence and Analytical Methods. Toxins (Basel), 11 (5), 290, 2019.

11. LYAGIN I., EFREMENKO E. Enzymes for Detoxification of Various Mycotoxins: Origins and Mechanisms of Catalytic Action. Molecules, 24 (13), 2362, 2019.

12. BARABASZ W., PIKULICKA A. Mycotoxins - a threat to human and animal health Part. 1. Mycotoxinscharacteristics, occurrence, toxicity to organisms. Journal of Heath Study and Medicine, 3, 65, 2017 [In Polish].

13. Commission Regulation (EC) No $1881 / 2006$ of 19 December 2006 setting maximum levels for certain contaminants in foodstuffs. Available online: https://eurlex.europa.eu/legal-content/EN/TXT/?uri=CELEX:0200 6R1881-20201014 (Accessed on 20.01.2021).

14. RUSU M.E.,FIZESAN I., POP A., MOCAN A., GHELDIU A.M., BABOTA M., BODNAR D.C., JURJ A., BERINDAN-NEAGOE I., VLASE L., POPA D.S. Walnut (Juglans regia L.) Septum: Assessment of Bioactive Molecules and In Vitro Biological Effects. Molecules, 25 (9), 2187, 2020

15. JAHANBAN-ESFAHLAN A., OSTADRAHIMI A., TABIBIAZAR M., AMAROWICZ R. A comparative review on the extraction, antioxidant content and antioxidant potential of different parts of walnut (Juglans regia L.) fruit and tree. Molecules, 24 (11), 2133, 2019.
16. SPADARO D., MELONI G.R., SICILIANO I., PRENCIPE S., GULLINO M.L. HPLC-MS/MS method for the detection of selected toxic metabolites produced by Penicillium spp. in nuts. Toxins, 12, 307, 2020.

17. NARVÁEZ A., RODRÍGUEZ-CARRASCO Y., CASTALDO L., IZZO L., GRAZIANI G., RITIENI A. Occurrence and Exposure Assessment of Mycotoxins in Ready-to-Eat Tree Nut Products through Ultra-High Performance Liquid Chromatography Coupled with High Resolution Q-Orbitrap Mass Spectrometry. Metabolites, 10, 344, 2020.

18. Commission Regulation (EC) No 401/2006 of 23 February 2006 laying down the methods of sampling and analysis for the official control of the levels of mycotoxins in foodstuffs. Available online: https://eur-lex.europa.eu/ legal-content/EN/TXT/PDF/?uri=CELEX:32006R0401\&fr $\mathrm{om}=\mathrm{pl}$ (Accessed on 20.01.2021).

19. Commission Regulation (EU) No $165 / 2010$ of 26 February 2010 amending Regulation (EC) No 1881/2006 setting maximum levels for certain contaminants in foodstuffs as regards aflatoxins. Available online: https://eur-lex.europa. eu/legal-content/EN/TXT/PDF/?uri=CELEX:32010R0165 $\&$ from $=$ PL (Accessed on 20.01.2021).

20. ADAYA-GONZÁLEZ J., CARVAJAL-MORENO M., ROJO-CALLEJAS F., RUIZ-VELASCO S. Aflatoxins in Walnut (Juglans regia L.), Pecan (Carya illinoinensis (Wangenh.) K. Koch) and Cashew (Anacardium occidentale L.) Nuts of Mexico. Pharmaceutica Analytica Acta, 6, 2, 2015.

21. GÜRSES M. Mycoflora and Aflatoxin Content of Hazelnuts, Walnuts, Peanuts, Almonds and Roasted Chickpeas (LEBLEBI) Sold in Turkey. International Journal of Food Propertie, 9 (3), 395, 2006.

22. Commission Regulation (EU) 2015/1137 of 13 July 2015 amending Regulation (EC) No 1881/2006 as regards the maximum level of Ochratoxin A in Capsicum spp. Spices. Available online: https://eur-lex.europa.eu/legal-content/ $\mathrm{EN} / \mathrm{TXT} / \mathrm{PDF} /$ ? uri $=\mathrm{CELEX}: 32015 \mathrm{R} 1137 \&$ from $=\mathrm{PL}$ (Aaccessed on 20.01.2021).

23. CIECIERSKA M., CHOJNACKA P., DERENIAKA D., DRUŻYŃSKA B., MAJEWSKA E., KOWALSKA J. Analysis of food chemical hazards on the basis of rasff reports. Bromat. Chem. Toksykol., 48 (3), 283, 2015 [In Polish].

24. RASFF- Rapid Alert System for Food and Feed. Available online: https://webgate.ec.europa.eu/rasff-window/port al/?event=searchResultList\&StartRow $=1 \quad$ (Accessed on 05.01.2021)

25. International Nut and Dried Fruit Council. Nuts \& Dried Fruits Statistical Yearbook 2019/2020. Available online: https://www.nutfruit.org/industry/technicalresources?category=statistical-yearbooks (Accessed on 05.01.2021). 